\title{
Development of a measure to assess the perceived illness experience after treatment for cancer
}

\author{
C Eiser, T Havermans, A Craft, J Kernahan
}

\begin{abstract}
The development of a scale to measure perceived illness experience in young people with cancer is described. Areas of concern were first identified through semistructured interviews conducted with children and adolescents. As a result, 78 items were generated to cover the main areas identified (physical appearance, interference with activity, peer rejection, integration in school, manipulation, parental behaviour, disclosure, preoccupation with illness, and impact of treatment). These items were rated (on five point scales) by 41 patients (mean age $14 \cdot 6$ years) and 35 of their parents. Measures of physical functioning (symptoms, functional disability, and restrictions) and psychological functioning (symptoms) were included for validation purposes. Test-retest reliability was calculated on the basis of ratings made by a subsample of parents on two separate occasions. A 34 item scale was constructed with four items in each of the areas identified above, except for physical appearance $(n=2)$. The scale has adequate internal reliability and validity. There were significant correlations between parents and their children on all subscales except for illness disclosure and impact of treatment, suggesting that parents may be less reliable informants for their children in these contexts. The scale has potential use in clinical contexts, in evaluating the psychosocial impact of different treatment regimens, and as an outcome measure in intervention work.
\end{abstract}

(Arch Dis Child 1995; 72: 302-307)

Keywords: adolescents, cancer, quality of life, parent-child relationship.

Recent statistics point to a continuing increase in survival from childhood cancer. ${ }^{1}$ However, treatment has been associated with adverse effects for both the child and family. ${ }^{2}$ For the child, there are the immediate consequences of treatment, interruptions in schooling and disturbed social relationships. More recently, longer term consequences, both physical and psychosocial, have also been noted. ${ }^{34}$

These findings suggest that a comprehensive assessment of outcome must include measures of psychological and social morbidity in addition to survival statistics. As a result, there has been a move toward assessment of quality of life to supplement traditional medical measures. At least two approaches can be distinguished in the assessment of quality of life. The first refers to more objective indices of health or functional status. Such a system has recently been described specifically for use in paediatric oncology. ${ }^{5}$ However, this lacks sensitivity and does not include all issues of importance to the child and family. ${ }^{7}$ It focuses heavily on functional ability, and was developed for use by medical staff, though has now been modified for use with families. ${ }^{8}$

The second approach acknowledges the subjectivity of quality of life. ${ }^{9}$ Based on findings of discrepancies between ratings of quality of life made by medical staff and families, this approach recognises that doctors are unable to make certain kinds of assessments, for example, how well the child gets on at school or pain experience. In fact, medical staff are necessarily dependent on families' accounts of these experiences and to a large extent rely on mothers for information.

Missing from much current work are data based more directly on the child's understanding of the disease and perceptions of the experience. Work which has involved children directly has focused largely on assessments of their knowledge or wish to be more involved in decision making. ${ }^{10}$ Nevertheless, this work suggests considerable differences between parents and their children in beliefs about the disease and its implications. ${ }^{11}$

The present study is an attempt to devise a method to assess the perceived impact of the illness from the child's point of view. Quality of life itself is best regarded as a multidimensional concept, and we focus on one aspect of this, the child's perception of the illness experience (PIE). While this is acknowledged to be central in many definitions of quality of life, it tends to be neglected in measurement instruments.

From a review of the literature, we found evidence to suggest that the following can contribute to the experience of illness in children with cancer: physical appearance, ${ }^{12}$ interference with activity, ${ }^{13}$ peer rejection, ${ }^{14} 15$ integration in school, ${ }^{16}$ manipulation or use of the illness to avoid obligations, ${ }^{17}$ family support and relationships, especially parental behaviour, ${ }^{18}$ willingness to discuss the illness with others, or disclosure (M A Chesler, paper given at the First International Meeting in Psychosocial Oncology for Social Workers, University of York, 1992), preoccupation with illness, anxiety about symptoms and recurrence of disease, ${ }^{19}$ and impact of treatment. ${ }^{20}$ While the clinical literature points to the importance of these factors in determining the impact of illness on children, the lack of a comprehensive instrument limits any 
assessment of the extent of difficulties in a population of young people with cancer.

We are not concerned with the extent to which behaviour is objectively limited by treatment, but with how far the child experiences any change to be personally stressful. Thus, the focus is not whether physical activity is actually curtailed, but with whether or not the child perceives this to be a problem.

In that the emphasis of such a measure is on the child's understanding of the illness, the acceptability of any scale cannot be determined simply in relation to more established measures which are based on parent's or physicians' ratings, and tend to be weighted toward assessment of physical functioning. However, in order to establish a degree of validity for our instrument, comparisons were made with previous measures. Following Mulhern, ${ }^{21}$ we included measures of physical functioning (symptoms, ${ }^{22}$ functional disability, ${ }^{23}$ and restrictions), and psychological functioning (symptoms ${ }^{22}$ ). Overall, we anticipated positive correlations between the child's total PIE score and general measures of physical and psychological functioning. We further anticipated correlations between certain subscales of the PIE scale and some previous measures. Given the significant overlap in content, we would expect that our assessment of 'interference with activity' would correlate with traditional measures of physical functioning. Other subscales, including 'physical appearance' and 'peer relationships', would also be expected to correlate with measures of physical functioning, given that children who look attractive and get on well with peers are more likely to be invited to join in with activities. In addition, some subscales, including 'peer relationships', 'integration in school', 'preoccupation with illness', and 'parental behaviour' would be expected to correlate with measures of general psychological functioning and symptomotology. Further subscales, such as 'illness disclosure' and 'manipulation', do not seem to be assessed directly in any established measures, and we therefore did not anticipate correlations between these subscales and other measures. A simple prediction regarding the relationship between the impact of illness and time since

Table 1 Demographic and medical information for the total sample of 41 children

\begin{tabular}{lc}
\hline & No of children \\
\hline Sex (M/F) & $20 / 21$ \\
Diagnosis & 28 \\
Acute lymphoblastic leukaemia & 6 \\
Wilms' tumour & 3 \\
Osteosarcoma & 2 \\
Non-Hodgkin's lymphoma & 2 \\
Rhabdomyosarcoma & $14 \cdot 6(4 \cdot 0)$ \\
Mean (SD) age (years) & $8 \cdot 0-24 \cdot 0$ \\
Range & $2 \cdot 1(1 \cdot 8)$ \\
Mean (SD) time since first diagnosed (years) & $0 \cdot 1-7 \cdot 9$ \\
Range & 17 \\
Treatment status & 24 \\
Maintenance treatment & 38 \\
Follow up only & 1 \\
Relapse & 1 \\
None & 1 \\
General & \\
Central nervous system & \\
Testicular & \\
\hline
\end{tabular}

diagnosis would be that impact would decrease as time since diagnosis increased. However, given the evidence of significant late effects in those who have completed treatment we did not make any definite predictions concerning this variable.

In this paper we therefore: report the development of a measure (PIE scale) for use with adolescents with cancer; describe the validity of the scale by relating the findings to more established measures of quality of life (physical and psychological functioning); and compare the scores obtained from the children with the scores from their parents in order to determine how far parents can be used as proxy respondents.

\section{Method for the development and validity of the measure}

SAMPLE AND PROCEDURE

The sample included 41 patients, treated in the children's cancer unit in Newcastle upon Tyne, who were able to complete the questionnaires themselves (mean age 14.6 years, range $=8-24)$. Table 1 shows the demographic and medical details of the 41 patients. Six attended clinic alone; the rest were accompanied.

Patients were approached when attending routine clinic appointments and asked to complete questionnaires concerned with the effect of illness and treatment. Approval to conduct the study was obtained from the local ethics committee.

\section{DEVELOPMENT OF THE PIE SCALE}

We followed procedures for scale construction as described by Oppenheim. ${ }^{24}$ Preliminary interviews were conducted with children and adolescents from the Royal Devon and Exeter Hospital $(n=15)$ who were undergoing treatment for cancer, or had recently completed treatment, to determine issues of concern to this age group. ${ }^{19}$ In these interviews, patients were asked to recall their experiences at specific critical points, including diagnosis, return to school and, where appropriate, completion of maintenance treatment. A set of 78 statements were derived from these interviews which broadly reflected the issues described above; eight of these were concerned specifically with the impact of treatment and were only completed by patients on maintenance treatment. The term 'cancer' was not used for two reasons. Firstly, some families have their own name for the illness, dislike the term cancer, and might object to their child completing such a scale. Secondly, by using the term 'illness' it is possible that the scale may ultimately prove useful for children with other chronic conditions. Parallel versions of the scale were developed which could be completed by children and their parents. (We used pronouns appropriate for the child's gender; thus, there were separate versions for parents of boys and girls.)

The questionnaires were introduced as 'some of the ways other people have told us 
Table 2 Example of items used to assess impact of illness on physical activity

My illness prevents me from doing my favourite games or sports

Because of my illness I am not always able to join in with what my friends are doing

I am usually too tired to go out after school or work

I am afraid of doing sports where I might get hurt

about how the illness affects their everyday lives'. Patients were asked to rate how much they agreed with each statement on a series of five point scales, where $1=$ 'disagree' to $5=$ 'agree'. Instructions to both parents and patients were that they should complete the questionnaires as they felt now, even though they might have responded very differently earlier in treatment. Examples are shown in table 2 .

Readability of the questionnaire was calculated with the Flesch formula. ${ }^{25}$ This is based on the average number of words per sentence and the average number of syllables per 100 words. Reading ease scores range from very easy 90-100 (equivalent to four years of formal schooling) to very difficult $0-30$ (equivalent to 15 years of schooling).

\section{QUESTIONNAIRES}

\section{Physical functioning}

Physical symptoms:- the Rotterdam symptom checklist $^{22}$ - In the absence of a measure to assess symptomatology in children with cancer, we used the Rotterdam symptom checklist, developed specifically for use with adults. This consists of 26 items describing physical and psychological symptoms. We used 17 of the original items to assess physical symptoms ('nausea' was excluded as we did not think the word would be understood by all children and would not be distinguished from 'sickness' which was retained in the symptom list).

The functional disability inventory ${ }^{23}$ - We included 13 items from the functional disability inventory which was designed to assess any difficulties experienced in performing everyday activities (walking upstairs, doing activities in the gym, getting to sleep at night). Items are rated on five point scales (from 'no trouble' to 'a lot of trouble'). The authors report good correlation between ratings made by children and their parents and that the scale has high internal consistency (interitem reliability $=0.92$ ).

Restrictions - This scale included seven items (sports, going out alone) which are rated in terms of how much the illness restricts participation in each activity.

\section{Psychological functioning}

Psychological symptoms - We included the same eight items to assess psychological symptoms as described in work with adults. ${ }^{22}$

Construction of subscales of the PIE scale - The original sample of 78 items was reduced on the basis of the patients' ratings. We attempted to select four statements for each of the subscales identified in the literature (physical appear- ance, interference with activity, peer rejection, integration in school, disclosure, manipulation, parental behaviour, preoccupation with illness, and impact of treatment). Statements were excluded which significantly reduced the reliability of each subscale. This procedure resulted in a scale including 34 items. All subscales included four items, apart from the physical appearance subscale which included two. Mean scores were computed for each subscale; in all cases higher scores indicate a greater impact. In addition, a total score was computed based on the mean score on the eight subscales.

Readability - The readability of the questionnaire was calculated to be within a range from fairly easy to standard (Flesch reading ease $=60-70$ ). Thus, it is suitable for adolescents who have completed seven or more years of formal schooling.

\section{Results}

MEAN SCORES AND INTERNAL RELIABILITY

The mean scores on the three established scales measuring physical functioning (physical symptoms, functional disability, and restrictions) were low, suggesting that patients perceived themselves to be relatively well and did not consider their physical functioning to be impaired. The mean score for psychological symptoms was also low. Together, these results suggest that the group was in relatively good physical and mental health.

Mean (SD) scores for the PIE scale and its subscales showed that the children used the whole range of the scale sufficiently. The internal consistency (interitem reliabilities) of the scale and subscales can be considered adequate for a newly developed instrument (see table 3).

VALIDITY: CORRELATIONS BETWEEN PIE AND ITS SUBSCALES WITH ESTABLISHED MEASURES OF PHYSICAL AND PSYCHOLOGICAL

FUNCTIONING (TABLE 4)

Physical functioning

As shown in table 3, there were significant correlations between physical symptoms and the

Table 3 Mean (SD) subscale scores and internal reliabilities (Cronbach's alphas) for the quality of life total score and subscale scores, physical and psychological functioning, and self esteem $(n=41)$

\begin{tabular}{lll}
\hline & Mean (SD) & Internal reliability \\
\hline Quality of life & & \\
Total score & $2.40(0.69)$ & 0.84 \\
Physical appearance & $2.07(1.33)$ & - \\
Interference with activity & $2.14(0.99)$ & 0.66 \\
Disclosure & $2.69(1 \cdot 10)$ & 0.68 \\
School & $1.94(1 \cdot 17)$ & 0.61 \\
Peer rejection & $2.27(1 \cdot 17)$ & 0.61 \\
Parental behaviour & $2.27(1.00)$ & 0.73 \\
Manipulation & $2.18(0.88)$ & 0.70 \\
Preoccupation with illness & $3.23(1.02)$ & 0.59 \\
Treatment & $2.46(1.03)$ & 0.64 \\
Physical functioning & & \\
Physical symptoms & $1.47(0.63)$ & 0.88 \\
Restrictions & $1.99(0.97)$ & 0.82 \\
Functional disability & $1.50(0.74)$ & 0.88 \\
Psychological functioning & & \\
Psychological symptoms & $1.64(0.74)$ & 0.84 \\
\hline
\end{tabular}


Table 4 Pearson correlations between quality of life subscale scores and established measures of physical and psychological functioning (patients' ratings, $n=41$ )

\begin{tabular}{|c|c|c|c|c|}
\hline & \multicolumn{3}{|l|}{ Physical } & \multirow{2}{*}{$\begin{array}{l}\text { Psychological: } \\
\text { psychological } \\
\text { symptoms }\end{array}$} \\
\hline & $\begin{array}{l}\text { Physical } \\
\text { symptoms }\end{array}$ & Restrictions & $\begin{array}{l}\text { Functional } \\
\text { disability }\end{array}$ & \\
\hline \multicolumn{5}{|l|}{ Quality of life } \\
\hline Total score & $0 \cdot 42^{\star}$ & $0 \cdot 32$ & $0 \cdot 40^{\star}$ & $0 \cdot 48^{\star \star}$ \\
\hline Physical appearance & $0 \cdot 38^{\star}$ & $0 \cdot 18$ & 0.33 & $0.43^{\star}$ \\
\hline Interference with activity & $0 \cdot 61^{\star \star}$ & $0 \cdot 40^{\star}$ & $0 \cdot 40^{\star}$ & $0 \cdot 57^{\star \star}$ \\
\hline Disclosure & $0 \cdot 22$ & 0.32 & 0.08 & $0 \cdot 33$ \\
\hline School & 0.04 & 0.32 & $0 \cdot 10$ & $0 \cdot 19$ \\
\hline Peer rejection & $0 \cdot 21$ & -0.01 & $0 \cdot 12$ & 0.21 \\
\hline Parental behaviour & $0 \cdot 17$ & $0 \cdot 37^{\star}$ & $0 \cdot 29$ & 0.03 \\
\hline Manipulation & $0 \cdot 19$ & $0 \cdot 31$ & $0 \cdot 16$ & $0 \cdot 40^{\star}$ \\
\hline Preoccupation with illness & 0.32 & -0.07 & $0 \cdot 34$ & $0 \cdot 24$ \\
\hline Treatment & 0.37 & $0 \cdot 07$ & $0 \cdot 29$ & $0 \cdot 27$ \\
\hline
\end{tabular}

${ }^{\star} \mathrm{p}<0.05 ;{ }^{\star \star} \mathrm{p}<0.01 ;{ }^{\star \star \star} \mathrm{p}<0.001$.

total PIE score, as well as with the subscales measuring physical appearance and interference with activity. Scores on the functional disability inventory correlated positively with interference with activity. The more children reported restrictions the more they also reported problems in terms of interference with activity and parental behaviour.

\section{Psychological functioning}

There were positive correlations between psychological symptoms and the total PIE score, and the three subscales measuring physical appearance, interference with activity, and manipulation. Thus, patients who reported more psychological symptoms also reported a more negative impact of the illness on subscales measuring physical appearance, interference with activity, and manipulation.

\section{Age and gender}

Younger children rated the impact of the illness on their physical appearance to be less than older children (mean (SD) 1.65 (2.00); $t=2.61, \quad \mathrm{p}<0.05)$. There were no other differences due to age or gender.

\section{Treatment status}

Those patients who had completed treatment were not, as might be expected, older than those still on maintenance treatment (mean

Table 5 Mean (SD) scores for adolescents' and parents' ratings of quality of life and established measures of physical and psychological functioning $(n=35)$

\begin{tabular}{|c|c|c|c|c|}
\hline & Adolescent & Parent & $\mathbf{r}$ & $t$ \\
\hline $\begin{array}{l}\text { Quality of life } \\
\text { Total } \\
\text { Physical appearance } \\
\text { Interference with activity } \\
\text { Disclosure } \\
\text { School } \\
\text { Peer rejection } \\
\text { Parental behaviour } \\
\text { Manipulation } \\
\text { Preoccupation with illness }\end{array}$ & $\begin{array}{l}2.42(0.63) \\
2.21(1.39) \\
2.15(1.01) \\
2.78(1.12) \\
2.01(1.17) \\
2.31(1.14) \\
2.38(1.03) \\
2.35(0.87) \\
3.28(1.04)\end{array}$ & $\begin{array}{l}2.56(0.54) \\
2.50(1.38) \\
2.06(1.17) \\
3.01(0.95) \\
2.17(1.03) \\
2.23(1.03) \\
2.49(1.09) \\
2.21(0.71) \\
3.28(0.86)\end{array}$ & $\begin{array}{l}0 \cdot 35 \\
0 \cdot 56^{\star \star} \\
0 \cdot 54^{\star \star} \\
0 \cdot 13^{\star} \\
0 \cdot 51^{\star} \\
0 \cdot 59^{\star \star \star} \\
0 \cdot 60^{\star \star \star} \\
0 \cdot 54^{\star \star} \\
0 \cdot 52^{\star \star}\end{array}$ & $\begin{array}{r}-1.07 \\
-0.27 \\
0.45 \\
-0.92 \\
0.79 \\
0.45 \\
-0.66 \\
0.98 \\
0.00\end{array}$ \\
\hline Treatment & $3.16(0.61)$ & $3.22(0.86)$ & 0.39 & -0.26 \\
\hline $\begin{array}{l}\text { Physical functioning } \\
\text { Physical symptoms } \\
\text { Restrictions } \\
\text { Functional disability }\end{array}$ & $\begin{array}{l}1.54(0.67) \\
2.02(0.91) \\
1.50(0.74)\end{array}$ & $\begin{array}{l}1.53(0.56) \\
1.91(0.74) \\
1.69(0.75)\end{array}$ & $\begin{array}{l}0 \cdot 84^{\star \star \star} \\
0 \cdot 62^{\star \star \star} \\
0 \cdot 81^{\star \star \star}\end{array}$ & $\begin{array}{r}0.19 \\
0.82 \\
-1.72\end{array}$ \\
\hline $\begin{array}{l}\text { Psychological functioning } \\
\text { Psychological symptoms }\end{array}$ & $1.72(0.75)$ & $1.84(0.95)$ & $0.56^{\star \star}$ & -0.78 \\
\hline
\end{tabular}

${ }^{\star} \mathrm{p}<0.05 ;{ }^{\star \star} \mathrm{p}<0.01 ;{ }^{\star \star \star} \mathrm{p}<0.001$
(SD) $14.8(14 \cdot 4)$ years). When comparing these two groups in terms of their PIE scores and other measures, differences were found on one subscale only. Those who had completed treatment reported that the impact of the illness on integration in school was greater than for those still on maintenance treatment (mean (SD) $2.5(1.6), \mathrm{p}<0.05)$

\section{Method to compare the use of proxy raters: comparisons between patients and their parents}

SAMPLE AND PROCEDURE

Where appropriate, accompanying parents were asked to complete a parallel version of the questionnaire. Data were obtained from 35 patient-parent pairs. The mean age of this subsample of patients was 14.4 years (range 8-20) and included 15 boys and 20 girls.

Total and subscale scores on all measures were computed for parents as described above for adolescents. Internal reliabilities for parents' scales were generally lower than for the patients (interference with activity 0.70 ; peer rejection 0.69 ; school 0.62 ; manipulation 0.42 ; parental behaviour 0.72 ; disclosure 0.56 ; preoccupation with illness 0.47 ; impact of treatment 0.36 ; total $0 \cdot 85$ ). When parents returned to clinic within a two month period during which the study was conducted $(n=28)$, they were asked to complete the PIE on both occasions, in order to establish testretest reliability.

\section{Results}

Test-retest reliability was acceptable for the total score $(r=0.92)$ and individual subscales (appearance $=0.54$; activity 0.67 ; disclosure 0.56 ; school 0.78 ; peer rejection 0.51 ; family 0.53 ; manipulation 0.66 ; preoccupation with illness $0 \cdot 85$ ). In order to determine parentchild agreement, a series of correlations were conducted between ratings given by parents and patients. There were significant correlations on all measures of physical and psychological functioning. There were no correlations between parents and children in terms of the total PIE score, nor on subscales measuring disclosure and impact of treatment. Correlations between parents and their children were significant for all other subscales. As correlations simply indicate a similar ordering in responses between adolescents and their parents, a series of $t$ tests were conducted to determine any significant differences on mean scores. These data are shown in table 5 and suggest no differences in mean ratings between adolescents and their parents for any of the measures.

\section{Discussion}

The proposed scale fulfils some initial requirements for an acceptable measure of perceived illness for use with adolescents with cancer. It is based on issues identified through the literature to be relevant specifically to children and adolescents with cancer. In addition, the 
statements used were made by adolescents and thus reflect their concerns, in their language, rather than being based on issues that are believed to be important by adults. The scale is multifactorial, and includes eight subscales to assess perceived impact on physical appearance, interference with activity, disclosure, integration in school, peer rejection, parental behaviour, manipulation, and preoccupation with illness. There is a separate subscale to measure the immediate impact of treatment, appropriate for those on maintenance treatment.

The PIE scale has acceptable levels of internal reliability and for parents, test-retest reliability. Construct validity was established through correlational analyses with measures of physical and psychological functioning. Total PIE scores correlated with established measures of physical and psychological functioning, suggesting a degree of validity with other measures. However, the pattern of correlations between specific subscales of the PIE scale and other measures varied, suggesting that our scale taps issues not assessed by traditional indices. As anticipated, the interference with activity subscale correlated with more established measures of physical functioning including physical symptoms, functional disability, and restrictions. There was only limited correlation between PIE subscales and psychological symptoms. Three other subscales in our scale (illness disclosure, preoccupation with illness, and impact of treatment) do not correlate with any established measures of physical or psychological functioning and therefore appear to tap areas quite distinct from more established measures.

The finding that those who had completed treatment reported more difficulties on the subscale measuring quality of life in school is not unexpected. A considerable body of work points to delayed achievements and educational disadvantage among long term survivors. ${ }^{26}$ While teachers and parents may be prepared to make allowances for the child who is on treatment, concerns about future academic success and employment opportunities may become more important for the child who has completed chemotherapy. With regard to other domains assessed, our results suggest that there is no simple linear relationship between time since diagnosis and psychological functioning. Future work needs to determine the difficulties that are unique to different phases of the treatment regimen.

The proposed scale overcomes some of the criticisms that have previously been made about measures used in the assessment of children with cancer. It is based on issues of concern to these children, rather than general behavioural measures developed for assessment of children with psychiatric problems or behavioural disturbance. It does not include somatic items which would inevitably inflate problem scores. ${ }^{27}$

In many practical contexts, it may be useful or necessary to use parents as proxy respondents for their children. Use of parents' responses should be considered with some caution. There was no significant correlation between ratings made by parents and children for the total PIE score. However, there were positive correlations for the individual subscales with the exception of those for disclosure and impact of treatment. This suggests that parents can be accepted as valid respondents for their children in specific areas. Differences do exist, however, particularly with regard to the extent to which children feel prepared to talk about the illness (the disclosure subscale) and impact of treatment.

The scale described is offered as a preliminary attempt to assess the specific concerns of young people with cancer, and as such has some advantages over more generic scales in current use. It has considerable face validity. Both parents and young people have spontaneously commented on how well it introduced issues which they personally considered to be important. It is suitable for routine clinic assessments as well as providing a basis for more in-depth counselling when needed. The format of the statements implies that others have previously reported these concerns and this may also enable young people to feel more confident to respond. Those who may be reluctant to discuss some issues in open interviews may be more willing (and able) to complete simple questionnaires. In addition, we believe the scale has potential value in clinical trials, as it specifically taps areas of concern to children and adolescents which are not an integral part of traditional measures. In that it does not refer to cancer specifically, the scale also has potential value in assessments with adolescents with other chronic diseases.

Christine Eiser and Trudy Havermans are funded by the Cancer Research Campaign (CP1019/0101)

1 Barr RD, DeVeber LL, Pai KM, et al. Management of children with acute lymphoblastic leukaemia by the Dana-Farber Cancer Institute protocols. $A m \mathcal{f}$ Pediat Hematol Oncol 1992; 14: 136-9.

2 Kupst MJ. Long-term family coping with acute lymphoblastic leukemia in childhood. In: LaGreca AM, Siegel LJ, Wallander $\mathrm{J}$, Walker CE, eds. Stress and coping in child health. New York: Guilford Press, 1992: 242-61.

3 Schwartz CL, Hobbie WL, Constine LS, Ruccione KS. Survivors of childhood cancer; assessment and management. St Louis: Mosby, 1994.

4 Eiser C, Havermans T. Long term social adjustment after treatment for childhood cancer. Arch Dis Child 1994; 70: treatme

5 Feeny D, Leiper A, Barr RD, et al. The comprehensive assessment of health status in survivors of childhood cancer: application to high-risk acute lymphoblastic leukaemia. Br f Cancer 1993; 67: 1047-52.

6 Feeny D, Furlong W, Barr RD, et al. A comprehensive multiattribute system for classifying health status of survivors of childhood cancer. BrF Cancer 1992; 10: 923-8.

7 Jenney MEM, Kane RL, Lurie N. Developing a measure of health outcomes in survivors of childhood cancer: a review of the issues. Med Pediatr Oncol (in press)

8 Billson AL, Walker DA. Assessment of health status in survivors of cancer. Arch Dis Child 1994; 70: 200-4.

9 Chibnall JT, Tate RC. The quality of life scale: a preliminary study with chronic pain patients. Psychological Health 1990; 4: 283-92.

10 Ellis $R$, Leventhal $B$. Information needs and decisionmaking preferences of children with cancer. PsychoOncology 1993; 2: 277-84.

11 Mulhern RK, Crisco JJ, Camitta BM. Patterns of communication among pediatric patients with leukaemia, parents and physicians; prognostic disagreements and misunderstandings. ₹ Pediatr 1989; 83: 480-3.

12 Varni JW, Setoguchi Y. Correlates of perceived physical appearance in children with congenital/acquired limb appearance in children with congenitalacquired
deficiencies. $\mathcal{f}$ Dev Behav Pediatr 1991; 12: 171-6. 
13 van Veldhuizen AM, Last BF. Children with cancer: communication and emotions. Amsterdam: Swets and Zeitlinger, 1992.

14 Spirito A, DeLawyer DD, Stark LJ. Peer relations and social adjustment of chronically ill children and adolescents. adjustment of chronically ill children and adolescents.
Clinical Psychology Review 1991; 11: 539-64.

$15 \mathrm{La} \mathrm{Greca} \mathrm{AM.} \mathrm{Social} \mathrm{consequences} \mathrm{of} \mathrm{pediatric} \mathrm{conditions:}$ fertile area for future investigation and intervention. 7 Pediatr Psychol 1990; 15: 285-307.

16 Charleton A, Larcombe IJ, Meller ST, et al. Absence from school related to cancer. and other chronic conditions. Arch Dis Child 1991; 66: 1217-22.

17 Eiser C, Town C. Teachers' concerns about chronically sick children. Implications for paediatricians. Dev Med Child Neurol 1987; 29: 56-63.

18 Binger CM. Childhood leukemia: emotional impact on patient and family. $N$ Engl $f$ Med 1969; 280: 414-8.

19 Eiser $C$. The impact of treatment: adolescents' views. In: Selby $\mathrm{P}$, Cunningham, $\mathrm{C}$, eds. Cancer and the adolescent. London: BMJ Publishing Group (in press).

20 Harris JC, Carel CA, Rosenberg LA, Joshi P, Leventhal BG. Intermittent high dose corticosteroid treatment in Intermittent high dose corticosteroid treatment in
childhood cancer: behavioural and emotional conse- quences. Fournal of the American Academy of Child Psychiatry 1986; 25: 120-4.

21 Mulhern RK, Horowitz ME, Ochs J, et al. Assessment of quality of life among pediatric cancer patients. 7 Consult Clin Psychol 1989; 1: 130-8.

22 Watson M, Law M, Maguire GP. Further development of a quality of life measure for cancer patients: the Rotterdam symptom checklist (revised). Psycho-Oncology 1992; 1: sympto 44 .

23 Walker L, Greene JW. The functional disability inventory: measuring a neglected dimension of health status. $\dot{f}$ Pediatr Psychol 1991; 16: 39-58.

24 Oppenheim AN. Questionnaire design, interviewing and attitude measurement. London: Pinter Publications, 1992.

25 Flesch RF. A new readability yardstick. $\mathcal{F}$ Appl Psychol 1948; 32: 221-33.

26 Madan-Swain RK, Brown RT. Cognitive and psychosocial sequelae for children with acute lymphocytic leukemia: a critical review and integrative analysis. Clinical Psychology Review 1991; 11: 267-94.

27 Walker DK, Stein REK, Perrin EC, Jessop DJ. Assessing psychosocial adjustment of children with chronic illnesses: a review of the technical properties of PARS 111 . $\mathcal{J} \mathrm{Dev}$ Behav Pediatr 1990; 11: 116-21. 